\title{
Digitalization as an Aid and Hindrance to Knowledge Management
}

\author{
Zimova N.S.* \\ Lomonosov Moscow State University \\ Moscow, Russia \\ e-mail:nzimova@mail.ru
}

\author{
Ksenofontova E.G. \\ Lomonosov Moscow State University \\ Moscow, Russia \\ e-mail: eksen@mail.ru
}

\begin{abstract}
Management and control depends on information in all areas. Therefore, the increasing capabilities of the information technology increase management potential. Trying to rely on the knowledge of all employees of the organization, top managers often care about collecting, exchanging and digitizing a large amount of data. However, this does not guarantee increased competitiveness of the organization. In the section "Heroical Sisyphus IT-tasks" by an example of comparing the results of a study of the difficulties and causes of professional burnout of IT specialists in Russia and the USA is shown that one of the main factors of their stress is the specific features of top-management work, in particular, their expectations and setting goals for implementation of the knowledge-management, not leading to the developing of a self-learning organization. Another factor of stress and failures in the knowledge management is associated with an increasing number of constantly updated types of information technologies, which is discussed in the section devoted to typical errors in supporting knowledge management projects, forecasts for the development of the IT-branch and problems of misunderstanding in communication of IT-specialists and other specialists in a company. The last section is devoted to the risks of treating knowledge as capital and the contradictions in the formulation of knowledge management tasks by HRmanagement of companies on one hand and specialists who have the opportunity to work as free-lance in the modern labor market conditions on another hand. Thus, it turns out that in the knowledge management not the amount of collected data, but its integration; does matter, not the large databases and not even the speed of their use, but the cooperative development of decisions based on the knowledge of the current situation, distributed among the company's employees. This managerial task can not be solved by digitalization methods. Although a reasonable reliance on the growing possibilities of digital technology may be very useful.
\end{abstract}

Keywords - IT-technologies of Knowledge management; Decision Support Systems; mistakes of top-management; aid and hindrance of digitalization; burnout.

\section{INTRODUCTION}

If in the management of simple technical systems decisions are made based on the information processing in the "control center or control units", and executed in the "operated devices", then the programming of the execution algorithms that are "embedded" in the execution object, relieves the control center and improves the efficiency of the system. In the social management dictators, shamans, authoritarian leaders ect. maximize information at their own pole and minimize any information at another pole, except to ensure that their influences are understood and executed. However, in the competition of social systems (as in market business activities), the involvement of all elements of the system in the development of the best solutions is expected to be based on the collection, processing of information and development of proposals (or decisions - with an appropriate transfer of the authority) by all members of the organization involved in the management of the common business. This is sometimes associated with one of the features of the knowledge society, as oppesed to the information society - where the role of every member was not outlined in such a significant way.[1].

Since information, being an immaterial substance, can describe any substances, increasing the integrity of information about them, the uncertainty of the information recipient decreases and he gets the ability to control: "due to the small amount of energy carrying information, to direct and control the movement and action of large masses or transmission and the conversion of large amounts of energy", - everyone who studies information theory is happy to say this quote [2].

In all centuries and with various technologies for obtaining information, the ability of the authority and, accordingly, the ability to direct and control the movement of the masses grew among those who possessed a large amount of the "necessary" information. However, over time, the quality of life of a person, as well as production and other systems that ensure their life activity, becomes more and more dependent (both positively and negatively) on the rapidly growing amounts of information. If at the beginning of the XX century the want of the mankind to improve the quality and convenience of social interaction was superimposed on the opportunities provided by the development of the means of communications, then in the late XX - the early XXI centuries the demand to improve the manageability and competitiveness of organizations was superimposed on the opportunities provided by the powerful development of the information technologies.

The processes of transfer to the digital formats of information, as before, the automation processes, do not immediately become not at once a convenient tools for a person, in fact forcing him to test the mechanisms of digitalization itself and forming great expectations for the reward ... in the future knowledge society. In the meantime, the "digital workforce" carries out a part of the production operations in the digital format, which encourages it to acquire new knowledge and develop new competencies, often not receiving "well-digitized" virtual or material "workplaces" 
from the employer. In particular, companies do not always provide instructions, organized trainings or licenses for the installation of software on computers of remote workers, that are useful for their work, but don't belong to the main software package.

Passing over to a new level of competition in the digital world is connected to a reliance on the possibility of a greater integration of the knowledge of all members of the organization, which allows turning the organization into a super-smart and goal-oriented acting integral entity. However, to the achievement of such a state is hindered by other digitalization trends that affect not only the actions of ITspecialists, but also the actions of HR-specialists and the topmanagement of the organization [3; 4].

\section{HEROICAL SISYPHEAN IT-TASKS}

It is inconceivable to imagine the knowledge management in an organization without the use of the information technology and without the participation of IT-specialists in maintaining this activity these days. However, management often does not invite it professionals to participate in the discussion of the goals, requirements, and capabilities of technologies for the next new project, and even chooses the architecture of solution without them. And the race begins!

Let us have a look at the everyday or rather round-theclock routine of IT-specialists of any organization. On the one hand, attempts are made to keep all products and semi-finished products of the office activity in one place. The structure even of uniform documents is different, the databank doesn't have much of a structure, a hierarchically organized storage requires the purchase of new servers, the cost of ownership is growing, the efficiency of use ....is expected sometime in the future. Mass users cannot find anything there and extract it, they are not even willing to undertake special actions in order to specify the terms of reference, because they don't see, what is incomprehensible: they just want everything to work and be at hand "like in a library". On the other hand, more and more information technology is used in cooperative work and in the existing archive or storage they want to implement analytics, change documents and, in general, simultaneously make changes to objects of joint development [5].

As with the automation of business processes, many understand that one won't save chaotically organized work using automation: one has to build it (work) up conceptually, and only then the "as is" state can be transferred to the "to be" state. Otherwise, there will be just some automated chaos. ITspecialists call attention to the conceptual differences in the knowledge base, expert support systems, artificial intelligence, and the database, management accounting systems and BI, document management systems and cooperative work systems. They are trying to define the rules of access, to develop the rules for cooperative work and persons who make final decisions in the system. They train the management, employees, beginners. They provide the system administration, technical support for users, make their own additions, transfer data from other systems.... And they quickly discover that this version of the system is not very convenient for users, so we should choose something more suitable and ensure the company's change-over to it. At the same time, all employees will have to ensure the "transfer" of their pages / sections / documents to a new platform, and all collective sections, that it is not very clear who needs at all, should be transferred by IT-specialists. In the free of other tasks time, i.e. in the night time.

The development of non-hierarchical networks, broadband Internet access from satellites, replicated (out-of-the-box) artificial intelligence solutions, new cloud solutions and services promises to make lifes of corporate IT-heroes easier over time. But new "challenges" arise - the fight against insider information and, in general, an increase in the sophistication of threats to the information security of an organization.

IT-specialists come to organizations more and more young, harness themselves to a bunch of interesting and complex tasks, learn, mutually develop in professional (mainly online) communities, and quietly "burn out". As they grow older, the demand for and criticality of IT-support will increase with respect to the top management of organizations in terms of the necessary answer to the question "Why to solve this mainly with IT-tools?", since the main knowledge management should be organized at a completely different level - of that very self-learning organization, which learns from its mistakes in the same way as artificial intelligence does. Only the progress of the last is much more obvious and no one has to be encouraged to knowledge sharing.

What do the results of the survey of 9 thousand ITspecialists conducted in 2018 by the North American Website Blind for professionals in this field [6] say? About $90 \%$ of them report signs of the professional burnout, among reasons for which for $19 \%$ is indicated overtime, for $18 \%$ - problems in the working atmosphere (the term "toxic environment" that is in trend now). And $23 \%$ of the reasons are associated with the special features of the organization's leadership: "Poor leadership and unclear direction". Among the reasons the inadequacy of reward is mentioned as well, but this is the last of the 5 groups of causes of the burnout. As the next-to-last is indicated the "lack of control and career growth".

What are the grounds for hoping that, in case of amplification priority of the knowledge management in Russia, IT-specialists will be have it easier than the 9000 polled by the North American website? Let's have a look at the results of a study of the similar Russian site "My Circle", conducted in 2019 [7]. About 2500 IT specialists were interviewed, with about $80 \%$ of them being at the age under 35 years, which reflects not only the visitor profile of the site, but also, in some way, the age structure of this profession. Over $50 \%$ noted that they experienced a state of burnout, while they observed burnout of their colleagues even more often. Its consequences meant for some of them not only the change of place of work or industry, but also the withdrawal from the profession. The authors of the study claim that only $25 \%$ of IT specialists remain at their old place of work (as a rule, if the management is seriously "correcting itself in something"), and the rest leave without having often worked even for 2 years in this organization (Fig. 1). 


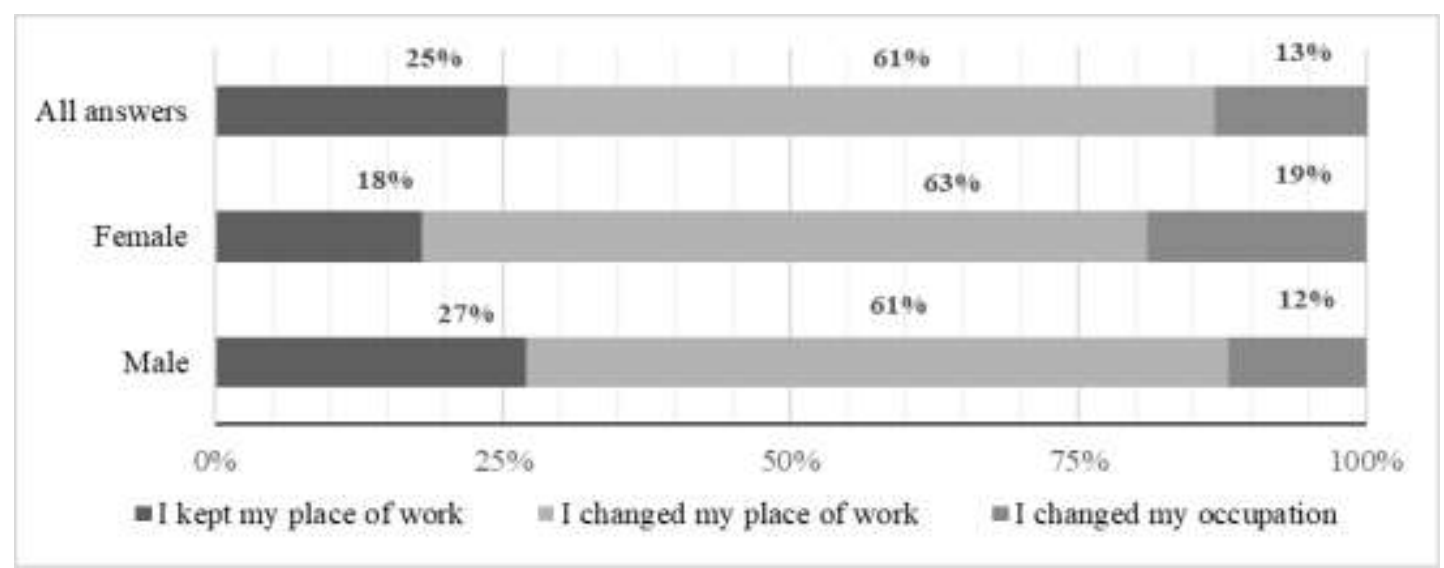

Fig. 1. The distribution of answers to the question of how the feeling of burnout ended

Let us compare how the causes of burnout coincide in studies conducted "on opposite sides of one and the same planet." The main sign noticed by $97 \%$ of Russian ITprofessionals experiencing burnout is a constant state of tiredness and empty feeling. This results in the loss of any motivation, indifference and formal performance of work.

And the main reasons for this situation turn out to be ... the same basic "managerial failures": an unclear task setting $69 \%$ and an unclear distribution of responsibilities $-62 \%$. The resulting lack of coordination of actions is $59 \%$. Not surprisingly, such an atmosphere in the team over time becomes "toxic." Overtime (like the Americans) is not in the first place, however, $49 \%$ of respondents register an excessive amount of work. The monotony of work (45\%) is sometimes combined with work in constantly changing conditions (39\%), but this is already registered less frequently than the previous one.

It is impossible to get rid of the feeling of burnout accumulated over a couple of years even by going on vacation. A change of employer is possible, if only because the demand for IT-professionals is constantly growing, and even more so for those who "had eaten a bushel of salt". However, many leave this field of activity completely. Because the incredible speed of the appearance of new technologies that must be tracked and mastered is excessively high, that deepens the feeling of constant stress and the need to catch up with the new knowledge with the new generations of IT-specialists

\section{COMMON MISTAKES IN THE KNOWLEDGE MANAGEMENT OF A COMPANY}

The development of computer decision support systems (DSS) and Business Intelligence (BI) has put into circulation a large number of terms that have a narrowly specific technical meaning. However, their literal "humanitarian interpretation" and their use as synonyms significantly complicates both the understanding of the terms of reference for specialists in the field of information technology and the understanding of developers' problems when fulfilling seemingly "simple" management requests [8].
IT-specialists see (though not always uniformly) the significant differences between the organization of "business intelligence" (BI) and the "Decision Support System" (DSS). When pronouncing the term "Management Expert System" they do not call for the development and involvement of experts among the staff, but they mean Suggestion DSS, which "offer" managers draft solutions based on either "Data mining" or "Text mining". While some take information from document files, others from the structured databases. In addition, the specifics of the Model-Driven Decision Support Systems of decision support systems and the CommunicationDriven DSS, or as they are otherwise called, Group DSS.

The growing race of "automation of everything" for several decades has led the company to the so-called "zoo" of heterogeneous (motley) programs, for the integration of which additional programs have to be created. However, in the final report of the international conference Gartner Predicts back in 2009, they emphasized that in order to increase business efficiency. The focus should be shifted from automation of operational activities to information support of analytical activities. Now, after 10 years, the information support has powerful opportunities for automation of collaborative operations. However, the organization of this collaboration cannot be reduced to endless database replenishment.

According to the Gartner's forecast for 2019-2022, the development of concepts in IT will continue to outpace the ability of organizations to keep up with them, many changes will seem more chaotic ... Therefore, more efforts will be needed to discern the need for a change in the way of thinking in the organization [9]. Nevertheless, technological development provides not only the drawing together of different approaches, but also their increasing orientation towards providing precisely collaborative knowledge systems and cooperative work systems. So, by 2022 , the convergence of the functionality of Content Collaboration Platforms and Content Services Platforms is expected, with a focus primarily on ensuring not so much operational autonomy as "collaboration". There is also a tendency to unite and expand "internal and external use" systems, which will not consider Web content management to be "knowledge only for external users" and managing communications with consumers will 
become part of "internal organizational concerns". Moreover, the authors of the review on IT-technologies specifically stipulate that it is impossible to achieve customer satisfaction by means of automation alone. It requires real interaction between the organization's representatives and the customers.

Like a whole class of computer decision-making programs is called the Knowledge-based System, we can also talk about Knowledge-based Management. In this case, the knowledge becomes a management or self-management tool for the collective achievement of the organization's goals, and not a target, as can be understood from the term Knowledge Management.

As Booth O.A. has figuratively showed, the priority of creating information support for the "knowledge flow" resembles the construction of a water supply system through which no water does flow [10].

\section{ATTITUDE TO KNOWLEDGE AS CAPITAL}

How and what knowledge can become a capital? Management specialists in technical systems clearly connect the effectiveness of individual "units" not with the "qualifications" of the control unit itself, but with the authority and ability to quickly receive the information it needs. With a decrease in the disorganization of the functioning of the system, the conditions for the timeliness of decision-making, as one of the factors of efficiency, improve [11]. And since the basis of management processes in any systems is information communication, the connection of all employees to work with the flows of information necessary for the "common cause" ("relevant knowledge") means a transition to a higher type of management - self-governing and self-developing organizations.

However, let us look through the eyes of an ordinary specialist: the intellectual capital (in combination with the individual social capital) increases its market value both in the labor market and in the outsourcing services market. Companies are becoming increasingly dependent: if earlier they acquired a specialist for long-term "use", now they are forced to buy portions of his professional services.

At the same the specialist loyalty to the customer company is less guaranteed than to the employer company, therefore the specialist has more freedom to offer his services to competitors of the current or previous customer on more favorable terms. One of the benefits for him is the interest of the tasks and their prospects from the point of view of developing even more professionalism, leading to an even greater cost of the services provided and the freedom of choice of the customer. The subject of market relations is increasing its capital.

Now we look at the same subject from the side of the company: intellectual capital (as a tangible part of its intangible assets) increases its market value precisely due to the increase in its competitiveness. In what case does this happen? With the effective joint use of diverse "distributed in the minds of employees" knowledge not only about the professional activity algorithms, but also about the current situation in their sections of the business process. But in this case, the focus should be on involving specialists of all levels in the joint solution of appearing operational and strategic tasks.

However, in companies, the emphasis is often placed on the collection and exchange of data requested by accounting and information systems, as it were for the future - for future use, which bothers the staff and sometimes even the company's customers (filling in all the fields required, for example, in a CRM system).

The T\&D - Training and Development personnel systems often work "for the future" as well. HR-specialists consider the knowledge management to be their natural responsibility. They perceive the personal development of each employee of the organization sometimes almost as the main way to increase the effectiveness of the organization. Though, of course, they also take care of the development of group interaction skills.

Top management does not mind that employees know more, share more knowledge and apply this knowledge in a better way. And the top management itself is usually occupied with more important tasks for business than the knowledge management which is delegated to a corresponding specialist or a functional unit.

The attitude to knowledge as a capital is associated with the resource model of strategic management and encourages the "accumulation" of knowledge as a strategic resource. But since often "the wrong knowledge" is accumulated "in the wrong way" to, it turns from a strategic resource into a burden, that hinders the flexibility of behavior in rapidly changing situations. The knowledge management becomes the management of the information body or data store, somewhat facilitating the management of not innovative production processes, but not more. Whereas the task of the knowledge management is to prepare for effective organizational behavior in the market, even in an environment of apparent chaos, or, as this term is somtimes simplified used - "at the edge of chaos". And in this context, researchers note a weak connection between the management of even unique resources, including the staff's unique knowledge and the creation of a real value that is significant for customers, as well as for other interested groups (stakeholders) [12]. The new logic requires relying not on the volume of knowledge, algorithms, "rules and standards", but on "soft management" and self-training in the form of competency building and their application in the process of joint problems solution, using and mastering many small and previously hidden knowledge and each other's skills.

\section{CONCLUSION}

Thus, it is important for an organization not to know more than others, but to recognize (calculate) market development trends faster than its competitors and, moreover, to implement quickly and in a coordinated manner rapidly developed new solutions. And no database, even a not very massive one, will be of any help in achieving this. Therefore, for the real reliance of management on "knowledge", it is necessary to organizationally ensure "the process of developing a new knowledge that is required right now" [13]. 
However, every new solution should not be a reinvention of the wheel. The specialists, motivated to solve the common problem, everyone having his own part of knowledge and being able to value and find what came before them, as well as save their own solutions in a convenient format (for quickly finding them in the future), fulfil their potential in this way, "standing on the shoulders of giants".

Thus, the conditions are created for the development of new flexible and constantly improving technologies for the interaction of all employees not only in the internal but also in the external environment, with the priority of the goal (focus on long-term results) over the process. It is important to stress that the focus on ensuring a sustainable development is insurance against relaying on the momentary temptation to apply the principle "the end justifies any means." The demanded by the company real participation of employees in solving business problems does not require the painful efforts of HR-specialists in inventing forms of staff involvement and increasing their organization loyalty. Moreover, in this case there is no reason to talk about low trust in the organization, which blocks the willingness of employees to "give" their knowledge to someone, because 4 important rules are followed: a) employees feel respect for them, b) respect the organization, c) help build a successful organizational future and d) see their place in it.

\section{References}

[1] N.P. Krasochenkova "National innivation space in the knowledge economy”, Strat. Decis. and risk manag., no. 5, pp. 44-48, 2016. Retrieved from: https://doi.org/10.17747/2078-8886-2016-5-44-48
[2] V. Lidovsky, "nformation theory - Study Guide. Moscow: Sputnik+, 2004, 111 p.

[3] S.S. Villalobos Gonzalez, E.L. Moreva, "The enterprise' IC management under the digitalization", Manag. Sci. in Russ., vol. 9, no. 3, pp. 78-85, 2019. DOI: 10.26794/2404-022X-2019-9-3-78-85

[4] N.S. Zimova, "Special aspects of implementing a knowledge management system in Russian companies", Sci. result. Sociol. and manag., vol. 5, no. 3, 2019. DOI: 10.18413/2408-9338-2019-5-3-0-7

[5] A.N. Biryukov, "How can an IT organization earn its customers' trust: A practical approach", Busin. Inform., vol. 13, no. 3, 2019, pp. 67-77. DOI: 10.17323/1998-0663.2019.3.67.77

[6] N. Kolakowski, Work Overload Isn't the Biggest Cause of Tech Worker Burnout, 2018. Retrieved from: https://insights.dice.com/2018/08/22/ work-overload-biggest-cause-tech-worker-burnout/

[7] Professional burnout in IT (Research results of "My Circle"). Retrieved from: https://habr.com/ru/company/habr_career/blog/437264/

[8] O.D. Kazakov, N.Yu. Azarenko, "The Model of Human Capital Management in Decision Support Systems", Proc. of VSUET, vol. 81, no. 3, pp. 290-298, 2019. (in Russian). doi:10.20914/2310-1202-20193-290-298

[9] The forecasts of Gartner. Retrieved from: https://www.gartner.com/en/ publications/top-tech-trends

[10] O. Booth, "Philosophical justification of Knowledge-based Management as a new management theory", Bull. of Tomsk state Univer., Philos. Sociol., Political sci., vol. 4, no. 20, 2012.

[11] A.N. Desyatirikov, Y.B. Nechaev, E.N. Desyatirikova, A.Y. Hestopalov, "Information analysis and synthesis of the organizational structure of the unique project in the classical control theory", Proc. of the Voronezh State Univer. of Engineer. Technol., vol. 80, no. 4, pp. 463-470, 2018. Retrieved from: https://doi.org/10.20914/2310-1202-2018-4-463-470

[12] A.D. Vorobyov, "Strategic management in the knowledge economy", Manag. Sci., vol. 8, no. 1, pp. 32-41, 2018.

[13] E.Yu. Blagov, S.A. Shcherban, "Managing organizational forgetting: The case of Russian machine manufacturing companies", Vest. of Saint Petersburg Univer., Manag., vol. 18, no. 2, pp. 261-287, 2019. Retrieved from: https://doi.org/10.21638/11701/spbu08.2019.205 